knew nothing about nor could cure schizophrenia.' The atmosphere then became depressive and there was a sense of panic and confusion. It seemed that, despite the real success of the meetings, the group was destined to end with an air of despair. Literally in the last few seconds, the most enthusiastic member of the group, James, said 'Oh schizophrenia! Will I be cursed with it forever?' After a few seconds of a very tense silence he continued, 'I'm sorry Dr Novosel. I get carried away sometimes. Don't worry about us, we'll be OK. Come back and see us when you can'.

With a few words James instantly transformed the atmosphere. The tension disappeared, to be replaced with a warm, relaxed, sad-but happy-feeling in everyone. It was a profoundly moving experience.

\section{Conclusion}

In attempting to describe my experience, I would like to indicate that group work with long term chronically psychotic patients can be successful. Too often such patients either do not have such meetings or, if they do, it is to 'receive' complaints or discuss who will wash up the dishes in the evenings.

In this experience, I felt that the group was therapeutic to both patients and staff. During the meetings a wide range of emotions were expressed and topics discussed which are too numerous to mention. I personally gained a greater understanding of what it means to live under conditions of maximum security and, more generally, what it means to live in a hospital for a period of years. The patients and staff felt that they gained the opportunity to sit down, as a group, and discuss issues that were important to them.

In describing my experience, I hope that consultants and their trainees might look at their 'chronic wards' and see that group meetings can be a valuable training experience. More importantly, they can be therapeutic to those patients and staff who frequently feel neglected and have a low morale.

The views expressed are completely those of the author and are not to be taken as representing the views of the Scottish Home and Health Department or of the Management Committee of the State Hospital.

ACKNOWLEDGEMENTS

I would like to express my gratitude to Dr Anne Macdonald, Consultant Forensic Psychiatrist, State Hospital for her supervision and support in establishing and running the group, to Mrs Beatrice McLelland for typing the minutes of the meetings and Miss Margaret Merrilees for typing the manuscript, to the nursing staff at the State Hospital for their enthusiasm and support in running the group and also, of course, the patients themselves without whom the group would not have been possible.

\title{
What Makes Psychiatric Summaries Useful to General Practitioners?
}

M. W. OrRell, SHO in Psychiatry, and M. Greenberg, Consultant Psychiatrists (Correspondence), Jules Thorn Day Hospital, University College Hospital, London NW1

A general practitioner needs to be kept well-informed when a patient with a psychiatric disorder is admitted to hospital. This can be difficult because a number of professional workers, not all of whom are hospital based, become involved in management, and confusion over clinical responsibility may develop. In these circumstances communication usually depends upon the hospital discharge summary ${ }^{1}$ which should contain information that is relevant to the GP's requirements.

Psychiatric discharge summaries are generally quite long and are extremely useful for hospital case records because they condense a considerable amount of information under organised headings. However, this does not necessarily mean that they meet the needs of GPs.

Previous investigations into communication between hospital doctors and GPs suggest that the latter are generally satisfied with the information they receive from hospitals and appreciate some explanation for the decisions that are reached. ${ }^{2,3.4}$ In these studies GPs consistently point out that certain information is lacking; in particular, they want to know what their patients or their patients' relatives have been told, and what follow-up arrangements have been made. Furthermore, they also believe there is an unnecessary delay between the time of a patient's discharge and when they receive the summary.

There has been no previous investigation specifically into psychiatric discharge summaries. We therefore set out to discover whether GPs have read the psychiatric discharge summaries we send them, whether they found them useful, whether they had any criticisms of them, and what factors might be associated with these findings.

\section{The study}

Following a pilot study, which involved detailed interviews with five randomly selected GPs listed within the catchment area of University College Hospital, London, a 38-item questionnaire was developed.

The questions covered their attitudes toward the following aspects of the psychiatric summaries they received: layout (e.g. 'Are the present summaries you receive far too long/ too long/ about right/ too short/ far too short?'); content (e.g. 'How frequently do the summaries which you receive at the moment contain adequate information on arrangements for follow-up? Always/ often/sometimes/ 
occasionally/ never.'); attention given them (e.g. 'To what extent do you actually read each summary which you receive? Thoroughly/almost completely/ partially/ superficially/not at all.'); usefulness (e.g. 'In general, how useful do you think that the summaries actually are? Exceptionally useful/ very useful/ quite useful/ of little use/ useless.'); and speed of delivery (e.g. 'How long after discharge do you usually receive the summary? One week or less/ two weeks/ three weeks/ four weeks/ five weeks or more'.) A space was included for additional comments.

The questionnaire was sent to all $55 \mathrm{GPs}$ in the catchment area, with a postal reminder after two weeks, and a telephone reminder two weeks later.

\section{The findings}

Response rate: Forty-one (75\%) of the 55 general practitioners responded. Of the 14 non-respondents, six had left the practice, two refused to answer, and six remained unaccounted for.

Usefulness: Forty respondents (98\%) read 'all' or 'most' of the summaries which they received, and $37(90 \%) \mathrm{read}$ each one 'thoroughly' or 'almost completely'. Thirty-one $(76 \%)$ 'often referred to the summaries on more than one occasion', and $33(81 \%)$ found the summaries either 'exceptionally useful' or 'very useful'.

Layout: Twenty-seven $(67 \%)$ of the GPs were satisfied with the length of the summaries and also with the amount of historical information they contained. Twelve (30\%) considered them too long and $10(25 \%)$ would have preferred less information. Twenty-four $(59 \%)$ would have preferred them printed on both sides of A4, rather than on separate sheets, because this was more convenient for filing.

Satisfaction: Table 1 summarises the differences between the GP' attitudes towards the inclusion of certain items and the frequency with which they were found. In addition, although $30(75 \%)$ believed that the amount of infor-

TABLE I

Necessity and adequacy of information provided to GPs $(n=41$ figures in percentages.)

\begin{tabular}{lcc}
\hline & $\begin{array}{c}\text { Essential } \\
\text { or very } \\
\text { important }\end{array}$ & $\begin{array}{c}\text { Adequately } \\
\text { provided } \\
\text { always or often }\end{array}$ \\
\hline Physical examination & 71 & 44 \\
Differential diagnosis & 63 & 29 \\
Investigations & 61 & 44 \\
Management & 98 & 76 \\
Drugs on discharge & 98 & 88 \\
Follow-up & 95 & 61 \\
Prognosis & 81 & 24 \\
Patient informed & 81 & 17 \\
Relative informed & 81 & 15 \\
\hline
\end{tabular}

mation provided on the mental state examination was 'about right', only $20(50 \%)$ believed it was 'very important' that the summaries contained a large amount of information on this.

Speed of delivery: Forty ( $98 \%$ ) of the GPs wanted to receive summaries within two weeks of their patient's discharge, but only $10(26 \%)$ thought this occurred. Thirty-six ( $88 \%)$ wanted a brief communication within forty-eight hours, and only $6(15 \%)$ thought this occurred.

Factors associated with usefulness: Inclusion of the following information was significantly associated with the perceived usefulness of the summaries: differential diagnosis $(P<$ $0.01)$ : prognosis $(P<0.05)$; follow-up details $(P<0.05)$. The usefulness was aiso significantly associated with how comprehensively each summary was read $(P<0.01)$. No correlation was found between the desirability of any particular information and the frequency of its presence.

\section{Comment}

These results suggest that psychiatric discharge summaries are generally read, used and valued. A typical comment was, 'It is very important that the mental state should contain a large amount of information for educational purposes, as well as clinical'.

However, summaries were also criticised because they lacked key information that is relevant to GPs, who particularly wanted to know what management decisions had been reached, who was responsible for carrying them out, what to expect in the future, and what the patient or relative had been told. A typical comment on this was, 'Very helpful on the whole, but often omit information about what the patient and relatives are told.' The GPs also wanted this information in a concise, easily-stored form, and would have liked to receive it before they next saw their patient. Comments on these issues included: 'I wish the summaries were shorter and sent to the GP's much earlier': 'I would like a summary of the summary, and an immediate, brief communication'; 'Printed both sides? Yes, for the sake of keeping files thin'; and '... for readmission, a shorter summary of the particular problem at the time is adequate.'

These findings have implications for training as well as for clinical practice. Psychiatrists need to be able to communicate clearly and effectively with their colleagues, as well as with their patients, and in order to do this they need to take account of what the recipient considers useful. Discharge summaries are generally written by psychiatric trainees, and therefore provide a useful opportunity for them to learn to develop their communication skills. This could be facilitated by retaining a structured outline $e^{5}$ and by concentrating on key areas ${ }^{4}$ which have consistently been shown to be appropriate to a GP's needs.

As a result of this study we have started to send brief discharge letters containing the key items suggested, within $\mathbf{4 8}$ hours of discharge and, when more immediate 
communication is appropriate, to contact GPs by telephone. Our intention is to assess whether this will lead to an improvement in communication.

\section{ACKNOWLEDGEMENTS}

We would like to thank Dr Chris Barker for his helpful advice about developing the questionnaire and about the statistical analysis and those general practitioners who generously gave their time during the preparation for this study.

\section{REFERENCE}

${ }^{1}$ LONG, A. \& AtkINs, J. B. (1974) Communications between general practitioners and consultants. British Medical Journal, iv: $456-459$.
${ }^{2}$ MARGO, J. L. (1982) Letters from psychiatrists to general practitioners Bulletin of the Royal College of Psychiatrists, 6, $139-141$.

${ }^{3}$ BADO, W. \& WILLIAMs, C. J. (1984) Usefulness of letters from hospitals to general practitioners. British Medical Journal, 288, 1813-1814.

4Pullen, I. M. \& Yellowlees, A. J. (1985) Is communication improving between general practitioners and psychiatrists? British Medical Journal, 290, 31-33.

${ }^{5}$ ANONYmous (1973) The hospital letter, (Editorial) Lancet, $i$, $245-6$.

\section{Working in Partnership. Lunch-time Meetings in Secondary Schools}

Jennifer A. Hayter, Locum Consultant Psychiatrist, Department of Child and Family Psychiatry, Canterbury, Kent

In their major piece of research, 'Fifteen Thousand Hours. Secondary Schools and their Effects on Children', ${ }^{1}$ Rutter and his colleagues showed how, with the right ethos, secondary schools could be a powerful force, promoting good outcomes over a range of measures, including attendance, exam results, behaviour in school and delinquency outside it.

Inspired by this, we, at the Canterbury Department of Child and Family Psychiatry, set about the task of exploring our interface with education, to determine how we might help to mobilise the therapeutic potential of local secondary schools for children in difficulties.

Our regular clinic meetings with the Canterbury educational psychologist to discuss the problems of children of mutual concern had already proved constructive. I had also happily participated for several years in in-service training courses for interested teachers, focusing particularly on 'Why children develop conduct disorder' and 'Psychiatric aspects of children with learning difficulties'. I had found teachers eager to understand why so many children foundered and anxious to learn how best to help. These contacts had already shown me how teachers often felt unsupported when trying to contain the problems of children with severe learning and behaviour problems. Often they struggled alone for too long, and when referral to us or to the School Psychological Service was made, there was a family in crisis, often alienated from the school. In the clinic too, we had long been aware that there were many more children in emotional difficulty than we were able to reach through the service we offered to children and their families.

So the challenge was to find a way to rally schools to be more effective therapeutic environments for children in difficulties; to help them to use child psychiatry and educational psychology efficiently by referring children at a stage when intervention had a better chance of success, and to work with us on therapeutic programmes, based on a clear identification of a particular child's needs.

Four years ago we set up a pilot scheme whereby we offered regular lunch-time meetings in secondary schools, once or twice a term, between myself as child psychiatrist, together with a clinic social worker from the Canterbury Department of Child and Family Psychiatry, the educational psychologist from the Canterbury School Psychological Service, and teaching staff concerned with pastoral care, as selected by the schools. We offered to discuss their problem children and to explore the interfaces between us, with the aim of working together more effectively to help the children in our care. This offer was taken up by four schools; in the past two years two more schools have joined the scheme.

We knew at the outset that for the meetings to be welcomed constructively, they had to detract as little as possible from the normal working commitments of the professionals concerned. We decided therefore to meet with our teaching colleagues over a working lunch, for one to one and a half hours. We hoped eating together would create an atmosphere of goodwill and help to break down inter-professional barriers. The arrangements varied from school to school. In some we ate in a room set aside for the meeting, where pupils helped to set the tables and deliver the food. In other schools we lined up in the school cafeteria with staff and pupils. This gave us an insight into the atmosphere of the school, and pupils saw us as an accepted part of an ordinary school day.

We learned that to keep a positive momentum the meetings had to be well organised in advance. Lists were exchanged of pupils put forward for discussion so that notes and relevant staff were available, and time was not wasted on half-remembered anecdotes. Schools found it 